\title{
RHINASTHMA-Children: A new quality of life tool for patients with respiratory allergy
}

To the Editor,

Recent research has focused on measuring the health-related quality-of-life (HRQoL) impact (physical, psychologic, and social) on children suffering from respiratory allergy. The burden of the disease has been evaluated by mean of different questionnaires specifically validated for asthma or allergic rhinitis. Several studies demonstrated that these two conditions often coexist, being seen in half to three quarters of children (1). The link between asthma and allergic rhinitis, as manifestation of the same inflammatory process according to the 'united airways' hypothesis, has been extensively showed. Therefore, the Allergic Rhinitis and its Impact on Asthma (ARIA) guidelines suggest the importance of an appropriate strategy combining safe and effective management of both diseases (2). Patients with both asthma and allergic rhinitis report a significant impairment of their physical health, so that being affected by these two conditions involves an additional burden in quality of life (3).

To date, no questionnaire permits to evaluate the impact of both upper and lower respiratory tract in children. The use of two different tools, one for rhinitis and one for asthma, in patients with comorbid conditions, represents a limit for HRQoL assessment in adults, in terms of time needed and repetition of items. In addition to these problems, when the patient is a child, lack of motivation and attention makes it difficult to obtain a specific assessment (4) of HRQoL in respiratory allergy. RHINASTHMA has been thought and validated to capture HRQOL in comorbid rhinitis and asthma for adult patients (5) and, more recently, for adolescents (6).

The purpose of this study was to develop and evaluate the psychometric characteristics of a new specific tool for the assessment of HRQoL in schoolchildren aged 6-11 years with respiratory allergy, starting from the idea underpinning the RHINASTHMA. The new questionnaire considers asthma and rhinitis as two clinical manifestations of the same disease, to globally evaluate the impact of respiratory allergy. This tool was intended to be (i) able to capture HRQoL in children with allergic rhinitis and/or asthma, (ii) generated and tested in accordance with procedures applied to HRQoL instruments, short, simple, and user-friendly, (iii) psychometrically sound with good validity and reliability, and (iv) easy to be completed by the patient himself. We have named this new questionnaire 'RHINASTHMA-Children'.

The validation procedure was performed in accordance with published guidelines (7). It consisted of two distinct phases (development and validation) involving different groups of patients. The method used for the two phases is described in detail below.

Children were consecutively recruited from April 2014 to December 2015 at the Pediatric Pulmonology and Allergology outpatient clinic of the IBIM CNR of Palermo, Italy. All patients underwent medical interview for clinical and family history, clinical visit, spirometry, and skin prick test (SPT) for the common allergens by well-trained physicians (V.M., G.F., S.L.G.). The HRQoL interviews were performed by welltrained psychologists (I.B. and L.M.). The participants were asked to read each question and respond aloud; when the children could not read by him/herself, the questions were read aloud by the interviewers. The answers were then challenged to make sure that the questions had been correctly understood.

The inclusion criteria required were age (6-11) and diagnosis of allergic rhinitis and/or asthma according to ARIA and GINA guidelines, respectively $(2,8)$. Children were eligible if they were native Italian speakers. Besides subjects who were $<6$ and $>11$ years of age, who reported upper respiratory tract infection or acute rhinosinusitis within 4 weeks prior to participation, and those with anatomic deformities causing airway obstruction (nasal polyposis, sinus disease, chronic nasal obstruction, and other serious diseases) were excluded from the study. None of the patients were smokers, nor on treatment with local or systemic antihistamines or steroids in the last four weeks prior the enrollment. All subjects included completed the study.

This study was performed according to Good Clinical Practice (GCP) standards and the Declaration of Helsinki and was approved by the local ethics committee $\left(\mathrm{N}^{\circ} 13 / 2013\right)$. For all patients included in this study, written informed consent was provided by parents.

In the items generation phase, a preliminary list of items was generated on the basis of the following sources:

1) An international literature review was performed on HRQoL assessment in children with asthma and allergic rhinitis;

2) A panel of pediatric allergologists (V.M., G.F., S.L.G.) and psychologists (I.B. and L.M.) who perform clinical and investigational research in the field of respiratory allergy was required to indicate symptoms and problems that may impact HRQoL of children with respiratory allergy;

3) Ten children with allergic rhinitis and asthma and their parents were interviewed by a clinician and a psychologist to identify those aspects of daily life that were impaired by the presence of respiratory allergy;

4) Two psychologists (I.B. and L.M.) with experience in the process of development and validation of quality-of-life questionnaires for chronic diseases were requested to adapt the items to a pediatric population.

In the items reduction phase, a qualitative selection was performed from the preliminary list of items by eliminating those that were redundant, ambiguous, difficult to understand, 
or expressed in the negative form. The resulting items were listed at random and administered to children with allergic rhinitis and asthma for the validation procedure. Each item was expressed as a five-point scale increasing with the importance given to that aspect: $1=$ not at all; $2=$ a little; 3 = enough; 4 = much; $5=$ very much. Patients had to indicate how much they had been troubled by each problem during the past week.

The questionnaire obtained from the first phase was validated (7). In particular, items were tested with a threefold objective: first, assessing consistency of the raw classification ('Activity limitations' and 'Symptoms') of the items and finding new potential subscales; second, assessing internal consistency within the obtained domains; third, evaluating divergent validity.

Factor analysis was performed on the questionnaire scores to identify the potential subscales. At this aim, the principal component method was used to extract the factors, and Oblimin rotation with Kaiser normalization was adopted to facilitate interpretability and therefore suitable labeling of the obtained subscales. Internal consistency was assessed using the Cronbach's correlation coefficient on the extracted factors. Divergent validity was assessed by means of Pearson correlation coefficients, evaluating the relationship between the new questionnaire and a generic HRQoL tool, the KINDL (9). KINDL includes six domains (physical well-being, emotional well-being, self-esteem, family, friends, and school). The subscales of KINDL are calculated such that a higher score corresponds to a higher HRQoL. Because the RHINASTHMA-Children evaluates specific health aspect, we did not expect the new questionnaire to be correlated with the generic HRQoL measures. In fact, KINDL assesses aspects of health status that are weakly related to respiratory allergy, especially in mild forms (e.g., headache and tummy ache, enjoying school, feeling fine at home, being bored). The statistical analyses were performed using the $\mathrm{R}$ statistical software version 3.2.0 [https://cran.r-project.org].

Starting from an initial list of 45 different symptoms and problems, 21 were selected and included in the questionnaire to be validated.

A total of 100 children were involved in the validation process. All the children completed the questionnaire answering to all the items (no missing values). Table 1 summarizes sample's demographic and clinical characteristics.

As the percentage of responses equal to 4 or 5 was lower than $15 \%$ for 17 items of 21 , these two response categories were aggregated and included in a more general category 'much' (together with response 3), resulting in the following new scale: $1=$ not at all (as before); 2 = a little (as before); $3=$ much (including previous categories 3,4 , and 5).

Factor analysis revealed the presence of five factors associated with eigenvalues greater than one; these five factors explained up to $68 \%$ of the total variance and therefore appear to be appropriate to summarize the existing relationship between the set of 21 items. Four items were excluded (Did you sleep well? Did you feel angry? Did you feel nervous? Does it bother you to have red crying eyes?) as allocation in the extracted dimensions was not well defined. The five factors
Table 1 Sample's demographic and clinical characteristics

\begin{tabular}{|c|c|}
\hline \multicolumn{2}{|l|}{ Demographic characteristics } \\
\hline \multicolumn{2}{|l|}{ Sex, $\mathrm{n}(\%)$} \\
\hline Males & $63(63 \%)$ \\
\hline Females & $37(37 \%)$ \\
\hline Age, years, (mean \pm s.d.) & $8.43 \pm 1.75$ \\
\hline Height, $\mathrm{cm}$, (mean \pm s.d.) & $129.95 \pm 11.52$ \\
\hline Weight, kg, (mean \pm s.d.) & $32.92 \pm 10.43$ \\
\hline BMI, $\mathrm{kg} / \mathrm{cm}^{2}$, (mean \pm s.d.) & $19.04 \pm 3.56$ \\
\hline \multicolumn{2}{|l|}{ Parental education, n (\%) } \\
\hline$\leq 8$ years & $7(7 \%)$ \\
\hline$>8$ years & $93(93 \%)$ \\
\hline \multicolumn{2}{|l|}{ Clinical characteristics } \\
\hline \multicolumn{2}{|l|}{ Rhinitis, n (\%) } \\
\hline Intermittent & $47(47 \%)$ \\
\hline Persistent & $53(53 \%)$ \\
\hline \multicolumn{2}{|l|}{ Asthma, n (\%) } \\
\hline Intermittent & $58(58 \%)$ \\
\hline Persistent & $42(42 \%)$ \\
\hline $\mathrm{FEV}_{1}, \%$ predicted, (mean \pm s.d.) & $(100.23 \pm 16.12)$ \\
\hline FVC, \% predicted, (mean \pm s.d.) & $(101.93 \pm 12.35)$ \\
\hline $\mathrm{FEV}_{1} / \mathrm{FVC}, \%$ predicted, (mean \pm s.d.) & $(97.97 \pm 12.90)$ \\
\hline $\mathrm{FEF}_{25-75}, \%$ predicted, (mean \pm s.d.) & $(88.29 \pm 21.40)$ \\
\hline
\end{tabular}

$\mathrm{BMI}$, body mass index; $\mathrm{FEV}_{1}$, forced expiratory volume in $1 \mathrm{~s} ; \mathrm{FVC}$, forced vital capacity; $F F_{25-75 \%}$, forced inspiratory flow 25-75\%.

were labeled according to the factor loadings (Table 2), which are related to the importance of each (latent) factor in explaining the (observed) items. Consistently with the initial raw classification, items related to symptoms are included within the same factors (splitted into two categories: lower and upper airways). The Cronbach's alpha values were computed for the five dimensions: 'Lower airways symptoms' (0.85), 'Low self-esteem' (0.76), 'Upper airways symptoms' (0.77), 'Social relationships' (0.76), and 'Medical care discomfort' (0.57). Internal consistency for the five factors is therefore satisfactory for the first four dimensions; despite lower if compared with others, consistency within the fifth dimension is above the minimum reliability standard of 0.50 . The correlations between RHINASTHMA-Children and KINDL were low (Table 3).

Individuals themselves are the most reliable and accurate observers of their health (10). In the past years, there has been a rapid expansion in the number of HRQoL instruments that are specifically designed and validated for the assessment of rhinitis and asthma in children. Nevertheless, all the available tools consider rhinitis and asthma as distinct diseases, making difficult to properly evaluate patients with comorbid conditions.

For these reasons, we attempted to develop and validate a specific HRQL questionnaire, suitable for children suffering from respiratory allergy, independent of their disease.

This study describes the development and initial validation of a new specific questionnaire aimed at assessing HRQoL of children with rhinitis and/or asthma. The RHINASTHMAChildren arises from the same idea that constitutes the basis of RHINASTHMA (5) and RHINASTHMA-Adolescents (6), 
Table 2 Factors identified by factor analysis (in bold typeface the items within each factors)

\begin{tabular}{|c|c|c|c|c|c|}
\hline Item & $\begin{array}{l}\text { Factor } 1 \\
\text { Lower } \\
\text { airways }\end{array}$ & $\begin{array}{l}\text { Factor } 2 \\
\text { Self-esteem }\end{array}$ & $\begin{array}{l}\text { Factor } 3 \\
\text { Upper } \\
\text { airways }\end{array}$ & $\begin{array}{l}\text { Factor } 4 \\
\text { Social } \\
\text { relationships }\end{array}$ & $\begin{array}{l}\text { Factor } 5 \\
\text { Medical } \\
\text { care discomfort }\end{array}$ \\
\hline Does whistle breathing bother you? & -0.886 & 0.062 & 0.042 & 0.040 & -0.198 \\
\hline Does breathlessness bother you? & -0.799 & -0.094 & -0.039 & -0.111 & -0.072 \\
\hline Does labored breathing bother you? & -0.759 & -0.105 & -0.119 & -0.045 & 0.010 \\
\hline Does having cough bother you? & -0.599 & -0.055 & -0.075 & -0.071 & 0.210 \\
\hline Have you been afraid of being sick? & -0.039 & -0.867 & -0.130 & 0.182 & -0.037 \\
\hline Have you felt sick? & -0.115 & -0.750 & -0.069 & 0.066 & -0.032 \\
\hline Have you felt different from your friends? & 0.123 & -0.700 & 0.053 & -0.041 & -0.104 \\
\hline Have you felt sad? & -0.171 & -0.654 & 0.227 & -0.360 & 0.160 \\
\hline Does sneezing bother you? & 0.085 & -0.018 & -0.909 & 0.071 & -0.060 \\
\hline Does frequent nose blowing bother you? & -0.003 & -0.119 & -0.816 & -0.118 & 0.087 \\
\hline Does stuffy nose bother you? & -0.292 & 0.169 & -0.614 & -0.114 & -0.048 \\
\hline Did you have attention problems at school? & 0.150 & 0.067 & 0.040 & -0.799 & -0.198 \\
\hline Did you have problems in playing and enjoyment? & -0.284 & -0.122 & -0.020 & -0.701 & 0.062 \\
\hline Did you have problems in tripping and going to parties? & -0.104 & 0.072 & -0.151 & -0.700 & -0.048 \\
\hline Did you have problems in running or doing sport? & -0.211 & -0.064 & -0.181 & -0.533 & 0.293 \\
\hline Does the need of assuming drugs bother you? & -0.331 & -0.010 & 0.020 & -0.033 & -0.823 \\
\hline Does the need of going to the doctor bother you? & 0.224 & -0.292 & -0.097 & -0.227 & -0.654 \\
\hline
\end{tabular}

Table 3 Pearson correlations between RHINASTHMA-Children and KINDL

\begin{tabular}{|c|c|c|c|c|c|}
\hline KINDL & $\begin{array}{l}\text { Factor } 1 \\
\text { Lower airways }\end{array}$ & $\begin{array}{l}\text { Factor } 2 \\
\text { Self-esteem }\end{array}$ & $\begin{array}{l}\text { Factor } 3 \\
\text { Upper airways }\end{array}$ & $\begin{array}{l}\text { Factor } 4 \\
\text { Social relationships }\end{array}$ & $\begin{array}{l}\text { Factor } 5 \\
\text { Medical care discomfort }\end{array}$ \\
\hline Physical well-being & $0.221 *$ & -0.04 & $0.219 *$ & 0.176 & 0.152 \\
\hline Emotional well-being & 0.172 & 0.035 & 0.153 & 0.13 & -0.023 \\
\hline Self-esteem & -0.111 & $-0.216^{*}$ & -0.167 & -0.02 & -0.015 \\
\hline Family & -0.134 & -0.192 & -0.178 & -0.014 & -0.125 \\
\hline Friends & -0.008 & -0.143 & 0.171 & 0.19 & -0.025 \\
\hline School & -0.193 & -0.042 & -0.168 & -0.108 & 0.002 \\
\hline
\end{tabular}

*p-value $<0.05$.

but it includes items that related to experiences, activities, and contexts that are relevant to pediatric age (4). Moreover, the new tool has been designed to ask questions in language and formats that children can understand, and it contains a limited number of items, to guarantee children's attention and engagement. The assessment of psychometric properties of the RHINASTHMA-Children provides evidence that the new tool met the standards for validity and internal consistency. Moreover, it is able to capture the specific impact of respiratory allergy on HRQoL, and it permits to integrate the information derived from a generic health status measure.

Validation is considered an iterative process, and this study constitutes the first phase in that process. Further work is planned to verify other psychometric characteristics of the new tool (i.e., responsiveness, test-retest reliability, and minimal important difference).

Ilaria Baiardini ${ }^{1}$; Salvatore Fasola ${ }^{2,3}$; Laura Montalbano ${ }^{2,4}$; Giovanna Cilluffo $^{2,3}$; Velia Malizia ${ }^{2}$; Giuliana Ferrante ${ }^{5}$ Fulvio Braido ${ }^{1} \&$ Stefania La Grutta $^{2}$

${ }^{1}$ DIMI, Allergy \& Respiratory Diseases Clinic, University of Genoa, IRCCS AOU San Martino-IST, Genoa; ${ }^{2}$ National Research Council of Italy, Institute

of Biomedicine and Molecular Immunology; ${ }^{3}$ Department of Economic, Business and Statistical Sciences; ${ }^{4}$ Department of Psychology; ${ }^{5}$ Department of Science for Health Promotion and Mother and Child Care, University of Palermo, Palermo, Italy

E-mail: ilaria.baiardini@libero.it DOI:10.1111/pai.12667

\section{References}

1. Ballardini N, Kull I, Lind T, et al. Development and comorbidity of eczema, asthma and rhinitis to age 12 years data from the BAMSE birth cohort. Allergy 2012: 67: 537-44.
2. Bousquet J, Khaltaev N, Cruz AA, et al. Allergic Rhinitis and its Impact on Asthma (ARIA) 2008 update (in collaboration with the World Health Organization, GA(2)LEN and Aller- Gen). Allergy 2008: 63: 8-160.
3. Braido F, Baiardini I, Balestracci S, et al. Does asthma control correlate with quality of life related to upper and lower airways? A real life study Allergy 2009: 64: $937-43$ 
4. Arbuckle R1, Abetz-Webb L. "Not just little adults": qualitative methods to support the development of pediatric patient-reported outcomes. Patient 2013: 6: 143-59.

5. Baiardini I, Pasquali M, Giardini A, et al. Rhinasthma: a new specific QoL

questionnaire for patients with rhinitis and asthma. Allergy 2003: 58: 289-94.

6. La Grutta S, Landi M, Braido F, et al. RHINASTHMA-Adolescents: a new quality of life tool for patients with respiratory allergy. Pediatr Allergy Immunol 2014: 25: 450-5.

7. Guyatt GH, Feeny DH, Patrick DL. Measuring health-related quality of life. Ann Intern Med 1993: 118: 622-29.

8. National Institutes of Health NH Lung and Blood Institute: global strategy for asthma management and prevention (Updated 2015): Global Initiative for Asthma (GINA), 2015, http://

www.ginasthma.org
9. Ravens-Sieberer U, Bullinger M. Assessing health-related quality of life in chronically ill children with the German KINDL ${ }^{\circledR}$ : first psychometric and content analytical results. Qual Life Res 1998: 7: 399-407.

10. DeCivita M, Reiger D, Alamgir AH, et al. Evaluating health-related quality-of-life studies in paediatric populations: some conceptual, methodological and developmental considerations and recent applications. Pharmacoeconomics 2005: 23: 659-685. 